\title{
Fairness and Team Efficiency
}

\author{
Petia Genkova \\ University of Applied Science, Osnabrueck, Germany
}

\begin{abstract}
This study applies to the perception of fairness during teamwork. Students were assigned to work groups by lot and were instructed to prepare a course presentation. Groups were given no guidelines relating to allocation of tasks, but each group was graded as a whole. Since a real grade was given in a non-simulated experiment, it was possible to determine team efficiency, work satisfaction, and perception of fairness via a subsequent study. Results show a strong influence of fairness on team efficiency.
\end{abstract}

Keywords: team efficiency, fairness, social loafing, performance appraisal

\section{Introduction}

Teamwork and team competence are keywords in today's world of work. Any employment ad or job description includes the demand to be a team player. On one hand, this claims more complex work processes, but on the other science veers toward work efficiency, group dynamic and process losses. Just like brainstorming was favored in the past, current results show that only teams with two members create new ideas efficiently and larger teams more likely block creativity. Rietzscheln, Nijstad, and Stroebe (2010) identified the strong tendency of participants to generate accomplishable and desirable ideas - at the expense of the originality of individual ideas - as reasons for poor performances in idea-finding processes. Indeed, the originality of individual ideas increases if candidates were explicitly ordered to create creative and original ideas. Moreover, this explicit order also decreased the candidates' satisfaction with the chosen ideas and they evaluated the ideas as less effective. According to Kohn and Smith (2011), the exchange of ideas in a brainstorming session reduces the number of domains of ideas that are explored by participants and the given ideas conform to ideas suggested by other participants. Paulus, Nakui, Putman, and Brown (2006) discovered that participants who periodically take a break produce more ideas at the end of the brainstorming session than participants that did not take a break. Several further studies analyzed group dynamic, team efficiency, and process losses (Weinert, 1998; Schuler, 2004). As perception of fairness is a key qualification, this influential variable was seldom explicitly related to team efficiency. This variable was commonly related to the process losses of teamwork.

Whether fairness influences team efficiency and acceptance of teamwork was analyzed by the means of this study. In addition, it studied to what extent perception of fairness and team efficiency influence work satisfaction. The study design occurred by chance. Actually, the goal was to give equal treatment to a large number of students in terms of their performance reviews. Time only permitted to allow group presentations and to grade each group as a whole. As a consequence, students claimed to be assigned to presentation topics and groups by lot. Although team competence is deemed to be socially desired and probably almost everyone

Petia Genkova, Ph.D., professor, Chair in Department of Business Psychology, University of Applied Science. 
wants to be described as social competent, a wave of disaffection occurred that gave the impulse for this study.

Even though Bales (1950) classified teamwork into task-orientated and social-emotional-orientated, the acceptance of teamwork is rarely explored. Next to "groupthink" and "groupshift", "social loafing" is also considered as an origin of danger in group work. Loafing at the cost of other group members influences individual efforts insofar as a growing group size reduces the individual contribution. Equality/inequality of efforts, attribution of personal responsibility, and loss of individual motivation due to an equally distributed reward are considered as causes of this group effect. The fact is that positive effects of group work are heavily decreased by social loafing and this always occurs when an individual cannot be assessed individually. Especially in individualistic cultures with high priority of self-interest, social loafing is strongly favored. Nevertheless, fairness is viewed rather from a social psychology perspective (e.g., equity-theory by Adams, 1965) than from an organizational psychology perspective (as cited in Rosenstiel, 2003). In a study by Price, Harrison, and Gavin (2006), student project groups were assessed over a period of 3-4 months. The results showed a negative correlation between the perception of fairness and the extent of social loafing. Aggarwal and O'Brien (2008) found that social loafing is positively linked with the scope of the project and the size of the group. However, multiple peer evaluation during the course of the project reduces social loafing. Alnuami, Robert, and Maruping (2009) suggested that social loafing may be conditioned by diffusion of responsibility and dehumanization in computer-mediated brainstorming sessions. Furthermore, the attribution of blame was quoted to have a negative effect on social loafing.

\section{Method}

\section{Sample}

A total of 108 students participated in this study: 80 female (74.1\%) and 28 male (25.9\%). The average age is 21.9 and all participants study in a new BA study program.

\section{Measuring}

As fairness is rarely explicitly studied, we developed a questionnaire which determines team efficiency and fairness. The questionnaire contained 23 items that were allocated to two scales: team efficiency and positive attitude towards teamwork (14 items, $\alpha=0.75$ ) and unfairness within teamwork ( 9 items, $\alpha=0.71$ ). The questions were responded to on a 7-point scale ranging from 1 ("Disagree") to 7 ("Agree"). Example items are: "I think that teamwork is unfair, because I always do more than other team members" and "It is unfair to be evaluated worse due to less deficient efforts and mistakes of some team members".

We also used a work satisfaction questionnaire by Duell and Frei (1986) with a 4-point scale from 1 ("Not important") to 4 ("Very important"). The questionnaire examines that criteria are experienced as important for individual work satisfaction $(18, \alpha=0.75)$ and the actual work conditions (19 conditions, $\alpha=0.77)$. The sample exclusively consisted of students. Therefore, the questionnaire was adapted to the students' work characteristics and items dealing with environment conditions, temperature and so on were excluded. Beyond that, a questionnaire was developed to record the acceptance of the random allocation by lot. The questionnaire contained 14 items $(\alpha=0.61)$ with a 7-point scale. The use of scales like "beliefs in a fair world" (Dalbert, 1996) did not seem necessary since the study's question was about fairness in teamwork. Example questions are: "If I can choose my tasks on my own, instead of being assigned to them, I am more motivated" and "I rather choose on my own and do not let others decide on my fate". 


\section{Hypotheses}

The following hypotheses were developed to determine the correlation between team efficiency and fairness:

Hypothesis 1: The ideal and the real work satisfaction are positively connected with perception of fairness within teams. Additionally, a positive relationship between allocation by lot and team efficiency can be expected.

Hypothesis 2: Team efficiency is predicted by perception of fairness.

Hypothesis 3: Gender differences in terms of perception of fairness, allocation to tasks by lot and work satisfaction are expected, as well as gender stereotypes accent the teamwork of women and the individual performance of men.

\section{Results and Discussion}

The results showed a positive correlation $(0.281, p<0.01)$ between ideal work satisfaction and team efficiency. No significant correlation was found between team fairness and real and ideal work satisfaction. Furthermore, the results show no significant correlation between allocation by lot and team efficiency. Therefore hypothesis 1 was only partially confirmed. Interestingly, not the real work satisfaction, but the ideal work satisfaction correlates with team efficiency. This suggests that the original attitude is more important than the actual framework conditions.

To check the second hypothesis linear regression analysis with enter procedure was performed. The dependent variable was team efficiency and independent variables were real and ideal work satisfaction, fairness within team and allocation of tasks by lot. The results confirmed this hypothesis. Both team fairness, perceived as unfair behavior $(\beta=-0.423, p<0.001)$, and ideal work satisfaction $(\beta=0.288, p<0.001)$ predicted team efficiency. However, explained variance is relatively small $\left(\Delta R^{2}=0.237\right)$ (see Table 1$)$.

Table 1

Regression Analysis Involving Team Efficiency as Dependent Variable

\begin{tabular}{|c|c|c|c|c|c|}
\hline Dependent variable & Unfairness within team & Ideal work satisfaction & Real work conditions & Allocation of tasks by lot & $R^{2}$ \\
\hline Team efficiency & $-0.423(p<0.001)$ & $0.288(p<0.001)$ & -0.041 & 0.129 & 0.266 \\
\hline
\end{tabular}

It should be noted that team fairness is the strongest predictor of team efficiency. Apparently, team fairness, initial acceptance of group work and low social loafing are crucial factors of successful teamwork and strongly determine team results.

To what extent the results differ in terms of gender differences (hypothesis 3) was checked using a variance analysis. Table 2 shows significant differences only relating to the allocation of tasks by lot (women $M$ $=4.04 ; S D=0.71 ;$ men $M=3.70 ; S D=0.58 ; F=5.081 ; d f=1,107$; and $p=0.026$ ). These differences can be explained by gender stereotypes, since allocation by lot instrumentally restricts individual options and gives equal opportunities to everyone.

These results prove that basic attitudes toward a task (in this case: which framework conditions are important for being satisfied with the task) are crucial in reference to what extent one can accept teamwork and works efficiently. The real work conditions as well as the method of allocation of tasks (by lot) do not influence team efficiency. In contrast, fairness and social loafing strongly predict team efficiency. The more fairness is 
perceived, the more efficiently a team works. These results do not detect new relationships, but show that sometimes changes of work conditions do not automatically lead to increased team efficiency. Acceptance of teamwork and efficiency are predicted by fairness. However, fairness can be regulated by the group itself and the group dynamic. This study was planned, among other things, as an evaluation of the course in that a large number of participants were instructed to prepare a course presentation with equality among the students. Accordingly, these hypotheses were derived from verbal feedback and were formulated. As results show, fairness was not decreased due to allocation by lot. As the groups had no guidelines relating to allocation of tasks, results show it is possible that the groups were not sufficiently team competent. To be fair also means to be successful within a team.

Table 2

Gender Differences in Terms of Teamwork

\begin{tabular}{|c|c|c|c|c|c|}
\hline & Sex & $M$ & $S D$ & $F_{(1,107)}$ & $p$ \\
\hline \multirow{3}{*}{ Unfairness } & Men & 4.06 & 0.82 & \multirow{3}{*}{0.002} & \multirow{3}{*}{0.962} \\
\hline & Women & 4.07 & 0.93 & & \\
\hline & Overall & 4.06 & 0.90 & & \\
\hline \multirow{3}{*}{ Team efficiency } & Men & 4.48 & 0.61 & \multirow{3}{*}{1.513} & \multirow{3}{*}{0.221} \\
\hline & Women & 4.27 & 0.82 & & \\
\hline & Overall & 4.33 & 0.77 & & \\
\hline \multirow{3}{*}{ Ideal work satisfaction } & Men & 2.90 & 0.39 & \multirow{3}{*}{1.443} & \multirow{3}{*}{0.232} \\
\hline & Women & 2.99 & 0.37 & & \\
\hline & Overall & 2.97 & 0.37 & & \\
\hline \multirow{3}{*}{ Real work satisfaction } & Men & 2.88 & 0.30 & \multirow{3}{*}{0.990} & \multirow{3}{*}{0.322} \\
\hline & Women & 2.95 & 0.33 & & \\
\hline & Overall & 2.93 & 0.33 & & \\
\hline \multirow{3}{*}{$\begin{array}{l}\text { Random selection } \\
\text { allocation of tasks }\end{array}$} & Men & 3.70 & 0.58 & \multirow{3}{*}{5.081} & \multirow{3}{*}{0.026} \\
\hline & Women & 4.04 & 0.71 & & \\
\hline & Overall & 3.95 & 0.69 & & \\
\hline
\end{tabular}

\section{References}

Aggarwal, P., \& O’Brien, C. L. (2008). Social loafing on group projects: Structural antecedents and effect on student satisfaction. Journal of Marketing Education, 30, 255-264.

Alnuaimi, O., Robert, L., \& Maruping, L. (2009). Social Loafing in Brainstorming CMC Teams: The role of moral disengagement. Proceedings of the 42nd Hawaii International Conference on System Sciences, Hawaii.

Bales, R. F. (1950). Interaction process analysis: A method for the study of small groups. Cambridge: Addison-Wesley.

Dalbert, C. (1996). Uncertainty tolerance and the dealing with injustice. In C. Dalbert (Ed.), About dealing with injustice (pp. 189-230). Bern: Huber.

Duell, \& Frei. (1986). Organizing the work-Letting workers participate: Heuristics of qualifying work structuring. Düsseldorf: Campus Verlag.

Kohn, N. W., \& Smith, S. M. (2011). Collaborative fixation: Effects of others' ideas on brainstorming. Applied Cognitive Psychology, 25, 359-371.

Paulus, P. B., Nakui, T., Putman, V. L., \& Brown, V. R. (2006). Effects of task instructions and brief breaks on brainstorming. Group Dynamics: Theory, Research, and Practice, 10, 206-219.

Price, K. H., Harrison, D. A., \& Gavin, J. H. (2006). Withholding inputs in team contexts: Member composition, interaction processes, evaluation structure, and social loafing. Journal of Applied Psychology, 6, 1375-1384. 
Rietzschel, E. F., Nijstad, B. A., \& Stroebe, W. (2010). The selection of creative ideas after individual idea generation: Choosing between creativity and impact. British Journal of Psychology, 101, 47-68.

Rosenstiel, L. V. (2003). Basics of the organizational psychology. Stuttgart: Schäffer-Poeschel.

Stroebe, W., \& Nijstad, B. A. (2004). Why brainstorming reduces the creativity in groups: A cognitive theory about the efficacy loss during the brainstorming. Psychologische Rundschau, 55(1), 2-10.

Schuler, H. (2004). Organizational psychology—Group and organization. Göttingen: Hogrefe.

Weinert, A. B. (1998). Organizational psychology_An educational book. Weinheim: Psychologie-Verlags-Union. 